\title{
Comparing the Effects of High Hydrostatic Pressure and Thermal Processing on Blanched and Unblanched Mango (Mangifera indica L.) Nectar: Using Headspace Fingerprinting as an Untargeted Approach
}

\author{
Fengxia Liu • Tara Grauwet • Biniam T. Kebede • \\ Ann Van Loey $\cdot$ Xiaojun Liao $•$ Marc Hendrickx
}

Received: 13 November 2013 / Accepted: 3 February 2014

(C) Springer Science+Business Media New York 2014

\begin{abstract}
The effects of high hydrostatic pressure and thermal processing on blanched and unblanched mango nectar were addressed by headspace GC-MS fingerprinting as an untargeted approach. Comparison between high hydrostatic pressure and thermal processing was performed based on the principle of equivalence. A considerable number of volatiles with higher concentrations were observed in unblanched mango nectar compared to blanched mango nectar. Both for high hydrostatic pressure and thermal processing, changes of mango nectar volatiles (composition and concentration) became more pronounced upon increasing processing intensity. However, based on a fair comparison, different process-induced chemical changes were detected for high hydrostatic pressure and thermal processing. For unblanched mango nectar, thermal processing seems to favor the formation of sulfurcontaining compounds (dimethyl sulfide), whereas high hydrostatic pressure seems to enhance the oxidation of free fatty acids, leading to increased concentration of aldehyde and alcohol volatile compounds (1-penten-3-ol, (Z)-2-penten-1-ol, and $(E)-2$-pentenal) in mango nectar. For blanched mango
\end{abstract}

F. Liu $\cdot$ X. Liao

College of Food Science and Nutritional Engineering, China Agricultural University, No. 17, Qinghua East Road, Haidian

District, Beijing 100083, People's Republic of China

F. Liu

e-mail: liufxia@gmail.com

F. Liu $\cdot$ T. Grauwet $\cdot$ B. T. Kebede $\cdot$ A. Van Loey $\cdot$

M. Hendrickx $(\square)$

Laboratory of Food Technology, Leuven Food Science and Nutrition Research Center (LFoRCe), Department of Microbial and Molecular Systems (M2S), KU Leuven, Kasteelpark Arenberg 22, Box 2457, 3001 Heverlee, Belgium

e-mail: marc.hendrickx@biw.kuleuven.be nectar, less significant differences were found between high hydrostatic pressure and thermal processing. This work demonstrates that different processing steps, for example blanching, high hydrostatic pressure, and thermal processing, have influence on the volatile profiles of the processed products.

Keywords High hydrostatic pressure $\cdot$ Thermal processing · Blanching $\cdot$ Headspace GC-MS fingerprinting $\cdot$ Mango nectar

\section{Introduction}

Mango (Mangifera indica L.) is a tropical fruit that originates from Southeast Asia and has been cultivated for at least 4,000 years (Santhirasegaram et al. 2013). It is of high economic importance in the international market, due to its vibrant colors, exotic flavors, distinctive taste, and nutritional properties (Singh et al. 2013). It has been reported that the consumption of mango can be linked to the prevention of cardiovascular diseases and cancer (Santhirasegaram et al. 2013; Liu 2003). Its processed products such as mango puree (Dougherty 1971), mango pulp (Ahmed et al. 2005; Liu et al. 2013a), mango nectar (Vásquez-Caicedo et al. 2007; Liu et al. 2013b), mango juice (Hiremath and Ramaswamy 2012; Santhirasegaram et al. 2013), and mango slices (Chen et al. 2007) are of high commercial importance. For a long time, thermal processing has been the preferred technology to achieve microbial inactivation and extend the shelf-life of food products (Rawson et al. 2011). However, thermal processing, particularly under severe conditions, may induce several chemical and physical changes that impair the organoleptic properties and may reduce the content or bioavailability of some bioactive compounds (Rawson et al. 2011). There have been reports that show significant quality losses in thermally 
treated mango fruit (Kim et al. 2009), mango slices (Chen et al. 2007), and mango nectar (Vásquez-Caicedo et al. 2007).

The growing interest in mildly processed products has facilitated the development of novel nonthermal food preservation methods (e.g., high hydrostatic pressure, pulsed electric field processing, high pressure carbon dioxide). High hydrostatic pressure is one of these alternative novel technologies which has the potential to improve the balance between safety and quality characteristics of currently thermally processed food products (Knorr et al. 2011; Oey et al. 2008b; Norton and Sun 2008). A wealth of scientific publications are available in which the effect of high hydrostatic pressure on food quality attributes is compared with that of conventional thermal processing, and high hydrostatic pressure-treated foods are generally claimed to have superior quality compared to their thermally treated counterparts (Huang et al. 2013; Dalmadi et al. 2007; Gimenez et al. 2001; Parish 1998; SánchezMoreno et al. 2006; Yen and Lin 1999; Oey et al. 2008a, b; Norton and Sun 2008; Liu et al. 2013b). However, most of these comparative studies have been conducted on targeted quality attributes (including specific nutrients, texture, flavor, color, and other relevant quality aspects) or evaluated a single response related to a specific reaction, which might result in overlooking unexpected effects.

Over the last decade, the application of fingerprinting techniques has emerged in the metabolomics research field with increasing interest to food scientists. They act as an untargeted, global screening approach, to classify samples by monitoring a wide range of compounds, instead of focusing on a particular component (Dettmer et al. 2007; Wishart 2008). Mass spectrometry (MS) with high selectivity and sensitivity, combined with a separation technique such as gas chromatography (GC), liquid chromatography (LC), or capillary electrophoresis (CE), is commonly used for sample analysis in metabolic fingerprinting research (Herrero et al. 2012; Bedair and Sumner 2008). The chromatogram of each sample can be considered as a fingerprint, which can subsequently be compared for samples processed by different methods, using multivariate data analysis techniques. It should lead to the selection of specific markers, compounds detected in different quantities comparing different conditions. These markers could be linked to possible reaction pathways or particular food characteristics (Dettmer et al. 2007; Wishart 2008; Vervoort et al. 2013; Kebede et al. 2013a). Since volatiles (including alcohols, aldehydes, furans, ketones, terpenes, and others) are often involved in process-induced reactions (e.g., Maillard reaction, Strecker degradation, oxidative degradation of unsaturated fatty acids and carotenoids), GC-MS measuring headspace volatiles of samples becomes one of the most widely used analytical techniques in the omics approaches (Bedair and Sumner 2008). Recently, headspace GC-MS fingerprinting has been proven to be effective for an unbiased comparison on quality changes due to different food processing, preservation, and subsequent storage condition afflicted to orange juice (Vervoort et al. 2012), green vegetables (Kebede et al. 2013a), carrots (Vervoort et al. 2013; Kebede et al. 2013b), onion, potato, pumpkin, and red beet (Kebede et al. 2013c).

The authors of this work have experience with studying quality changes in mango products during pasteurization and storage. In their published papers (Liu et al. 2013a, b, c), the effect of high hydrostatic pressure and thermal processing of mango pulp/nectar was compared using a targeted analytical approach, by analyzing a wide range of quality attributes including specific (micro)nutrients (L-ascorbic acid, carotenoids, phenols, and sugars), process-induced contaminants (5-hydroxymethylfurfural), antioxidant activity, and other relevant quality aspects (viscosity and color). To complement the study, the objective of the current work is to address this comparison using headspace GC-MS fingerprinting as an untargeted approach, zooming in to uncover and compare potential process-induced food quality changes.

\section{Materials and Methods}

\section{Sample Preparation}

Mature green mango fruits (M. indica L., cv. Kent) were purchased at a local market in Leuven, Belgium. The fruit samples were ripened at room temperature $\left(20-25^{\circ} \mathrm{C}\right)$ for about 4 days until fully mature $(\mathrm{pH} 3.70 \pm 0.01$, total soluble solid $20.25 \pm$ $0.03^{\circ} \mathrm{Bx}$ ). They were then washed, peeled, and deseeded, and the flesh was cut into small pieces ( $1 \mathrm{~cm}$ thickness). Since headspace volatile changes of mango nectar may be attributed to enzymatic and chemical reactions during processing and thawing, both of these reactions were considered in this study. The slices were divided into two equal portions. In order to prevent all enzymatic reactions during processing (to completely inactivate all enzymes) and to assure only changes during high hydrostatic pressure and thermal processing, the first portion of mango slices was vacuum-sealed in low-density polyethylene bags and blanched at $95^{\circ} \mathrm{C}$ for $8 \mathrm{~min}$ in a water bath (WB 22, Memmert GmbH \& Co. KG, Germany). The second portion was used to prepare unblanched mango nectar, taking into account the enzymatic reaction during different processing.

Unblanched or blanched mango slices were mixed with water (1:3, grams per milliliter) and blended in a kitchen blender to get a uniform nectar. The $\mathrm{pH}$ of the nectar was adjusted to $3.95 \pm 0.01$ with citric acid (Acros organics, Geel, Belgium), and the total soluble solid was adjusted to $10.0 \pm 0.10^{\circ} \mathrm{Bx}$ with sucrose (Applichem GmbH, Darmstadt, Germany).

\section{Processing Conditions}

Mango nectar was packed and subjected to different processing conditions: no processing (control), high pressure 
processing at $600 \mathrm{MPa} / 1 \mathrm{~min}(\mathrm{HP} 1)$, high pressure processing at $600 \mathrm{MPa} / 3 \mathrm{~min}(\mathrm{HP} 2)$, and thermal processing according to different pasteurization values $F_{85}^{8.3}{ }^{\circ} \mathrm{C} C=5 \mathrm{~min}(\mathrm{TP} 1)$ and $F_{93.3{ }^{\circ} \mathrm{C} C}=15 \mathrm{~min}(\mathrm{TP} 2)$. HP1 was selected to achieve a 5$\log$ reduction of Escherichia coli $\mathrm{O} 157: \mathrm{H7}$, assuring microbial safety of mango juice, and HP2 was selected targeting 6-8 $\log$ reductions of $E$. coli $\mathrm{O} 157: \mathrm{H} 7$, as recommended to ensure shelf-life stability of mango juice (Hiremath and Ramaswamy 2012). TP1 was selected according to an industrially relevant pasteurization value $\left(F_{85}^{8.3{ }^{\circ} \mathrm{C}} \mathrm{C}=5 \mathrm{~min}\right)$ for thermal processing of fruit juices (pH 3.7 to 4.2 ) to assure stable shelf-life, while TP2 was applied to study the effect of severe thermal pasteurization on headspace volatile changes in mango nectar. As HP2 and TP1 were processing conditions recommended to result in microbial stability, comparison between these two conditions could be considered as a fair comparison between high hydrostatic pressure and thermally treated mango nectar.

High hydrostatic pressure processing was carried out using a laboratory-scale high pressure unit (custom-made, Resato, The Netherlands), equipped with six vertically oriented individual vessels (volume $=43 \mathrm{~cm}^{3}$ and diameter $=2 \mathrm{~cm}$ ). The vessels were jacketed with a coil connected to a temperature controlling unit. Sample pressure (Fig. 1, dotted line) and temperature (Fig. 1, dashed line) can be automatically recorded. The pressure medium was $100 \%$ propylene glycol (PG fluid, Resato, The Netherlands). Teflon sample holders (12 $\mathrm{mm}$ inner diameter, $85 \mathrm{~mm}$ length, $4 \mathrm{~mm}$ wall thickness, Vink, Belgium) were filled with mango nectar and closed with a movable cap and vacuum-sealed in plastic bags. Before high pressure processing, both the sample holders and high pressure vessels were pre-equilibrated at $10{ }^{\circ} \mathrm{C}$. Thereafter, the

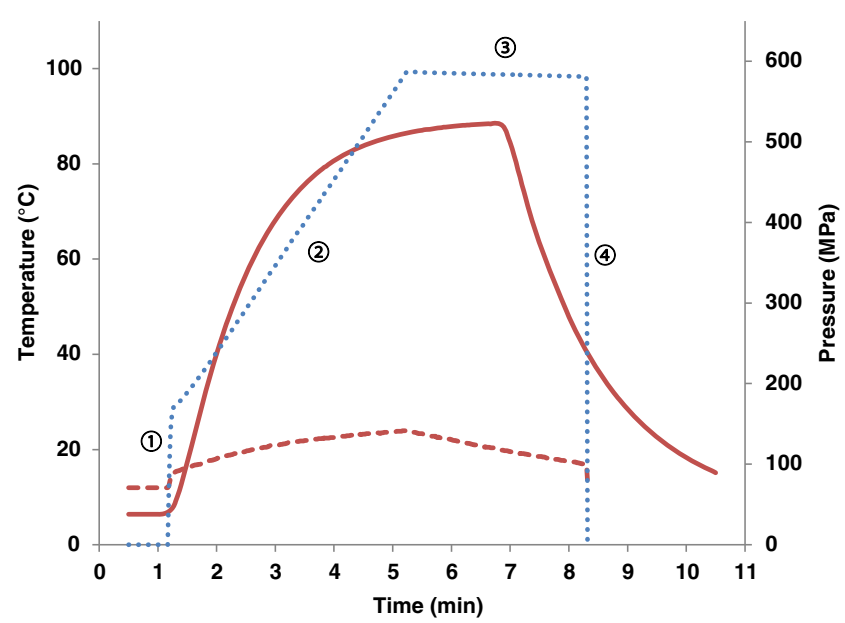

Fig. 1 The profiles of HP2 treatment with sample temperature (dashed line) and pressure (dotted line) and TP1 treatment with sample temperature (solid line). For HP2 treatment, sequential steps were followed: 1 fast pressure build-up to $150 \mathrm{MPa}$; 2 slow pressure build-up from 150 to $600 \mathrm{MPa}$ in $4 \mathrm{~min}$, to ensure sample temperature below $25^{\circ} \mathrm{C}$ during processing; 3 the pressure was maintained at $600 \mathrm{MPa}$ for a holding time of $3 \mathrm{~min}$; 4 fast pressure release, which is associated with a fast temperature drop pressure was immediately built up to $150 \mathrm{MPa}$ and then slowly built up to $600 \mathrm{MPa}$ in $4 \mathrm{~min}$. After reaching $600 \mathrm{MPa}$, the individual vessels were isolated and the pressure was maintained for a holding time of 1 (HP1) or $3 \mathrm{~min}$ (HP2), and then the pressure was released immediately. The temperature was never higher than $25^{\circ} \mathrm{C}$ throughout the processing, to reduce thermal impact as much as possible.

Thermal processing was carried out in glass reactor tubes in a temperature-controlled water bath (WB 22, Memmert GmbH \& Co. KG, Hannover, Germany), and a constant holding temperature of $90^{\circ} \mathrm{C}$ was selected for both TP1 and TP2 treatments. Temperature profile (Fig. 1, solid line) was recorded at the geometric center of the sample in a tube using a type $\mathrm{T}$ thermocouple connected to a thermocouple box (TR9216, Ellab, Hilleroed, Denmark) and a CMC-92 data acquisition system (Ellab, Hilleroed, Denmark).

Each treatment was repeated six times. Special care must be taken to minimize the formation or degradation of volatiles due to remaining enzyme activity in unblanched mango nectar. Thus, samples were kept in ice water prior to and immediately after various processing to avoid any enzymatic reaction. Subsequently, treated samples were transferred to polyethylene terephthalate tubes with a volume of $10 \mathrm{~mL}$ in a cooling room $\left(4{ }^{\circ} \mathrm{C}\right)$ and frozen in liquid nitrogen. Unblanched mango nectar was stored at $-80^{\circ} \mathrm{C}$ and blanched mango nectar was stored at $-40{ }^{\circ} \mathrm{C}$ until further analysis.

\section{Headspace GC-MS Analysis}

Each sample tube was thawed overnight in a cooling room $\left(4{ }^{\circ} \mathrm{C}\right)$. To ensure detection of a wide range of volatiles in mango nectar, the headspace SPME-GC-MS method was optimized beforehand. In the method selected, amber glass vials (10 mL, VWR International, PA, USA) were filled with $5 \mathrm{~g}$ mango nectar and $1.8 \mathrm{~g}$ solid $\mathrm{NaCl}$ and then closed tightly using screw caps with PTFE/silicon septum seal (GRACE, Columbia, MD, USA). After homogenization, the vials were placed into the cooling tray of the autosampler which was maintained at $10^{\circ} \mathrm{C}$. Headspace analysis was conducted on a GC system (7890B, Agilent technologies, Diegem, Belgium) coupled to a mass selective detector (MSD) (5977A, Agilent Technologies, Diegem, Belgium). Sample vials were equilibrated at $40{ }^{\circ} \mathrm{C}$ for $20 \mathrm{~min}$ under agitation at $500 \mathrm{rpm}$. Subsequently, volatile compounds in the headspace were extracted using SPME fibers coated with $50 / 30 \mu \mathrm{m}$ divinylbenzene/ carboxen/polydimethylsiloxane (DVB/CAR/PDMS) (StableFlex, Supelco, Bellefonte, PA, USA) at $40{ }^{\circ} \mathrm{C}$ for $10 \mathrm{~min}$. The fiber was then desorbed at $230{ }^{\circ} \mathrm{C}$ for $2 \mathrm{~min}$ in the injection port. Each fiber was conditioned according to the manufacturer's guidelines before its first use. Injection of the samples to the GC column was performed in split (1/5) mode. Volatile compounds were separated on HP-5MS capillary column $(30 \mathrm{~m} \times 0.25 \mathrm{~mm}$ i.d., $0.25 \mu \mathrm{m}$ film thickness, Agilent 
Technologies J\&W, Santa Clara, CA, USA), using helium as carrier gas at a constant flow of $1.2 \mathrm{~mL} / \mathrm{min}$. The $\mathrm{GC}$ oven temperature was programmed from a starting temperature of $40^{\circ} \mathrm{C}$ for $2 \mathrm{~min}$, and then the temperature was increased to $160{ }^{\circ} \mathrm{C}$ at a rate of $4{ }^{\circ} \mathrm{C} / \mathrm{min}$, followed by a second ramp to $300{ }^{\circ} \mathrm{C}$ at $50^{\circ} \mathrm{C} / \mathrm{min}$. After maintaining $300{ }^{\circ} \mathrm{C}$ for $2 \mathrm{~min}$, the oven was cooled again to the initial temperature. The mass spectra were obtained by electron ionization (EI) mode at $200 \mathrm{eV}$ with a scanning range of $35-400 \mathrm{~m} / \mathrm{z}$ and a scanning speed of 3.8 scans per second. MS ion source and quadrupole temperatures were 250 and $150{ }^{\circ} \mathrm{C}$, respectively.

\section{Data Preprocessing and Multivariate Analysis}

For a detailed description of the data preprocessing and multivariate analysis, the reader is referred to Kebede et al. (2013a). It will only be discussed in brief in this study. As shown in Fig. 2, the data set obtained in this study was examined by multivariate data analysis at different levels: firstly, the effect of raw material blanching was studied, represented by solid arrows; secondly, the effect of a range of different processing technologies and intensities was addressed for each blanching condition, indicated by dashed arrows; thirdly, the process effect of fair high pressure and thermal processing conditions was compared, shown by dotted arrows.

All chromatograms obtained were analyzed with the Automated Mass Spectral Deconvolution and Identification System (AMDIS) (Version 2.66, 2008, National Institute of Standards and Technology, Gaithersburg, MD, USA) to extract "pure" component spectra from complex chromatograms. In addition, AMDIS can be configured to build a retention index calibration file and to use retention index data along with the mass spectral data for compound identification. The deconvoluted spectra were then analyzed with Mass Profiler Professional (MPP) (Version 12.0, 2012, Agilent Technologies, Diegem, Belgium) for filtering and peak alignment. From these steps, a spreadsheet consisting of samples (rows) versus variables (column) was obtained, in which the detected peak areas were calculated. The resulting spreadsheet was

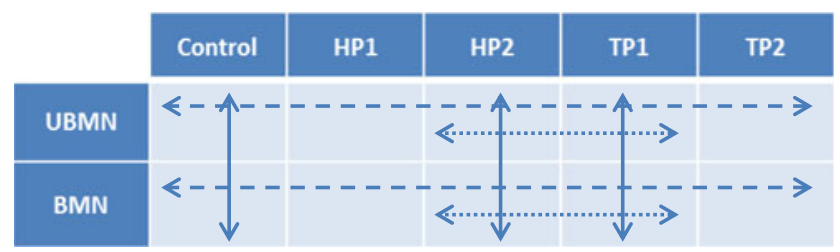

Fig. 2 Schematic overview of the setting up for performed headspace volatiles analysis. Based on the data set obtained, different effects were studied: (1) effect of blanching treatment (solid arrows); (2) effects of processing technology and intensity (dashed arrows); and (3) comparison of high pressure and thermal processing based on equivalent processing conditions (dotted arrows) then used as an input for multivariate data analysis (MVDA), carried out using Solo (Version 6.5, 2011, Eigenvector Research, Wenatchee, WA, USA). All data were meancentered and the variables were weighed by their standard deviation to give them equal variance. MVDA is extremely useful for extracting important information from these large data sets by reducing the information to a few latent variables. In addition, MVDA can graphically describe the separation between the sample classes in the multivariate space and illustrate the importance of each variable for the classification. One of these graphs is a bi-plot, generated based on partial least squares discriminant analysis (PLS-DA), with the headspace components as $X$-variables and different treatments as categorical $Y$-variables. However, the bi-plot cannot quantitatively show the component's relevance. As a quantitative measure for selection of discriminant compounds, variable identification (VID) coefficients were calculated (Vervoort et al. 2012). Positive VID values can be linked to higher concentration of the selected discriminant components for that processing technology compared to the others. The higher the absolute VID value, the higher the discriminative power of the variable for that class and vice versa. In our case, variables with an absolute VID value higher than 0.800 were considered as important and were plotted individually for different processing conditions using OriginPro 8 (Origin Lab Corporation, Northampton, MA, USA). Identification of these compounds was performed by their retention index and comparing the mass spectrum with the reference mass spectrum from the NIST spectral library (NIST08, version 2.0, National Institute of Standards and Technology, Gaithersburg, MD, USA). A Duncan's multiple comparison was used to test for significant differences between the mean peak areas $(p<0.05)$ of the discriminant components.

\section{Results and Discussion}

In total, 37 headspace components were detected over all chromatograms obtained in unblanched mango nectar and 26 in blanched mango nectar. As shown in the representative total ion chromatogram of control blanched mango nectar (Fig. 3), $\Delta$-3-carene was detected as the prominent volatile in this study, displayed at retention time of $16.2 \mathrm{~min}$. The results were consistent with previous literature data reporting $\Delta$-3-carene to be the major volatile in Kent mango cultivar, comprising more than $73 \%$ of the total aroma compounds (Pino and Mesa 2006). The data of this work were analyzed by multivariate data analysis at different levels: screening the effect of blanching, screening the effect of a range of different processing technologies and intensities per blanching condition, and comparing the process effect of fair high pressure and thermal processing conditions. These different effects are updated and discussed separately below. 
Fig. 3 Total ion chromatogram of reference mango nectar (blanched) obtained by SPME-GC-MS

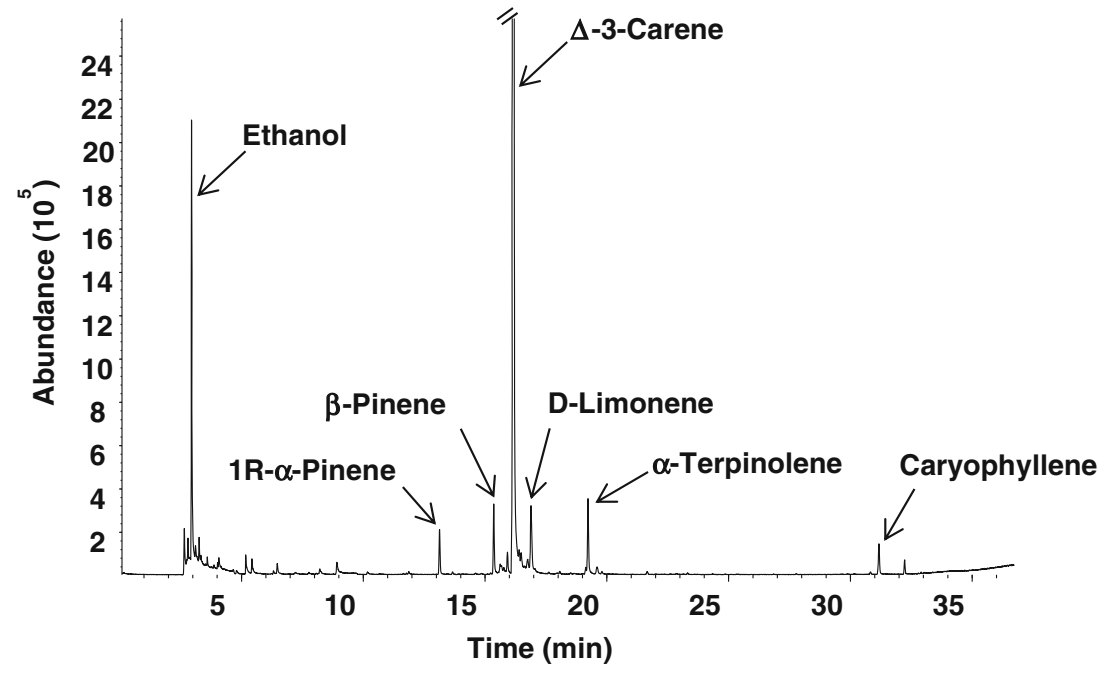

\section{Screening the Effect of Blanching}

To clarify the effect of blanching, a comparison was made between the headspace profiles of unblanched and blanched mango nectar, both with their control, HP2-, and TP1-treated counterparts, and the differences in processing intensities were not taken into account in the PLS-DA analysis at this step. The bi-plot based on the first two latent variables (LV) was generated and shown in Fig. 4. The mango nectar volatiles were considered as $X$-variables, while the unblanched and blanched mango nectar as categorical $Y$-variables. It is apparent from the results that this analysis leads to a clear distinction of unblanched and blanched mango nectar, with $90.53 \%$ of $Y$ variance explained by the first $L V$, indicating that significant differences between the volatile profiles could be found. Moreover, it is interesting to see that the samples within the class of blanched mango nectar were clustered much closer to each other in the bi-plot, than in the case of unblanched mango nectar. Although it is not very pronounced, a clear trend within the class of unblanched mango nectar could be noted, with
Fig. 4 A bi-plot based on PLSDA describing impact of blanching processing of mango nectars, with unblanched (black triangles) and blanched (black squares) samples indicated by different filled symbols.

Processing intensity is marked by color scale (control (black), HP2 (gray), and TP1 (light gray)), but this information is not included in PLS-DA analysis at this step. The open circles represent the headspace components, of which only the selected discriminant components (bold open circles) are named (Table 1). The correlation loadings for the categorical $Y$-variables are represented as vectors. The $X$ - and $Y$-variance explained by each LV are indicated in the respective axes

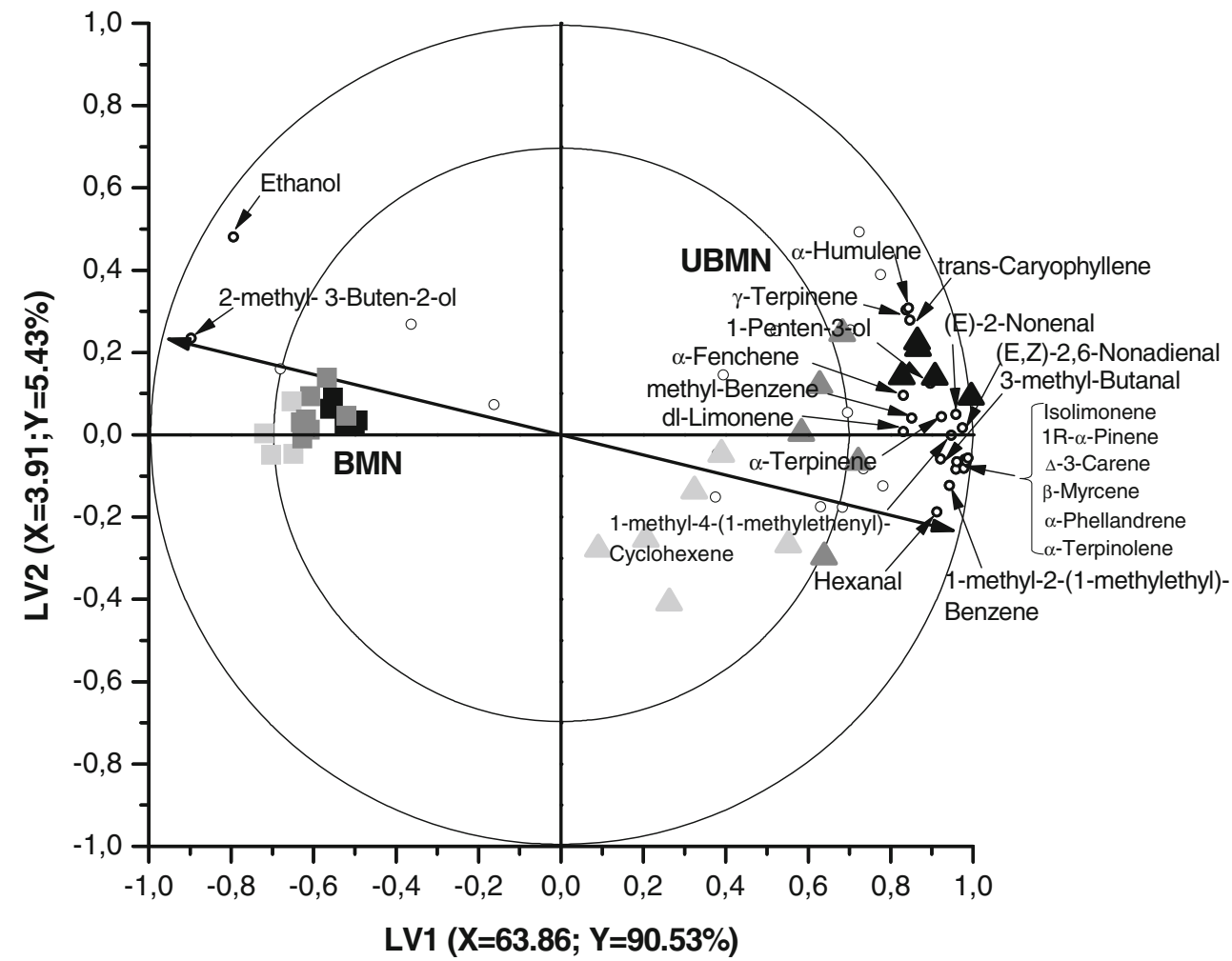


treated samples projected closer to blanched mango nectar. This is logical, because in this study, the selected blanching condition $\left(95^{\circ} \mathrm{C} / 8 \mathrm{~min}\right)$ was more intense than the actual processing conditions of HP2 and TP1.

In addition to illustrating the relations between different classes, the bi-plot also contains information about the importance of each headspace component for the classification. In the bi-plot, volatile components between the inner and outer ellipses (correlation coefficients of 70 and $100 \%$, respectively) can be considered as important for the classification. For these components, more than $70 \%$ of their variability is explained by the first two LVs. The importance of these components depends on their distance from the center. To be more detailed, the volatiles that are projected far away from the center and close to a certain class or far away at the opposite side of the bi-plot are respectively highly positively or highly negatively correlated to the corresponding class (Vervoort et al. 2012). Moreover, to quantitatively show the components' relevance, VID coefficients were calculated. Components with an absolute value of more than 0.800 were considered of potential interest and were listed in Table 1, in a decreasing order of VID coefficient. Only components with positive VID coefficients are displayed, since the ranked list is identical, but in reversed order. These selected components are also marked in the bi-plot in Fig. 4.

As shown from the listed numbers in Table 1, it is clear that a considerable number of the components selected were found with positive VID coefficients in unblanched mango nectar, including 13 terpenes, 4 aldehydes, 1 alcohol, and 2 other hydrocarbons. This observation can also be visualized, in Fig. 4, as most headspace components are projected towards the unblanched mango nectar class. From the individual plots (results not shown), it seems that most of the selected terpenoid compounds ( $\alpha$-terpinolene, $\alpha$-phellandrene, $\beta$-myrcene, $\Delta$-3-carene, $1 \mathrm{R}$ - $\alpha$-pinene, 1-methyl-4-(1-methylethenyl)-cyclohexene, $\alpha$-terpinene, DL-limonene, $\alpha$-humulene) and hexanal are significantly lower for blanched samples. The decrease in terpenoids could be attributed to thermal-induced terpernoid degradation, as reported by Kebede et al. (2013a) for thermally treated pepper puree. Hexanal was reported to be the result of enzyme-catalyzed oxidation of unsaturated fatty acids (i.e., linoleic acid and linolenic acid) (Cremer and Eichner 2000). Thus, the decrease in hexanal in this study could result from thermal inactivation of enzymes in the mango nectar and was consistent with previous reports. Correa et al. (2009) found that hexanal was degraded due to
Table 1 Discriminative headspace components, selected for blanching treatment of mango nectars. The headspace components are listed in a decreasing order of VID coefficients, where a positive VID coefficient indicates a higher concentration for that class. The retention index (RI) of these components are also listed

\begin{tabular}{|c|c|c|c|c|c|}
\hline \multicolumn{3}{|c|}{ UBMN } & \multicolumn{3}{|l|}{ BMN } \\
\hline VID & Identity & RI & VID & Identity & RI \\
\hline 0.990 & $\alpha$-Terpinolene & 1,093 & 0.909 & 2-methyl-3-Buten-2-ol & 689 \\
\hline 0.985 & $\alpha$-Phellandrene & 1,006 & 0.822 & Ethanol & 660 \\
\hline 0.981 & $\beta$-Myrcene & 991 & & & \\
\hline 0.981 & $\Delta$-3-Carene & 1,013 & & & \\
\hline 0.971 & $(E, Z)-2,6-$ Nonadienal & 1,156 & & & \\
\hline 0.963 & 1R- $\alpha$-Pinene & 932 & & & \\
\hline 0.956 & Isolimonene & 1,002 & & & \\
\hline 0.954 & (E)-2-Nonenal & 1,162 & & & \\
\hline 0.948 & 1-methyl-2-(1-methylethyl)-Benzene & 1,027 & & & \\
\hline 0.946 & 1-methyl-4-(1-methylethenyl)-Cyclohexene & 1,031 & & & \\
\hline 0.923 & 3-methyl-Butanal & 706 & & & \\
\hline 0.922 & Hexanal & 801 & & & \\
\hline 0.919 & $\alpha$-Terpinene & 1,019 & & & \\
\hline 0.887 & 1-Penten-3-ol & 718 & & & \\
\hline 0.847 & methyl-Benzene & 774 & & & \\
\hline 0.830 & DL-Limonene & 1,028 & & & \\
\hline 0.828 & trans-Caryophyllene & 1,449 & & & \\
\hline 0.823 & $\alpha$-Humulene & 1,503 & & & \\
\hline 0.823 & $\alpha$-Fenchene & 946 & & & \\
\hline 0.817 & $\gamma$-Terpinene & 1,062 & & & \\
\hline
\end{tabular}

$U B M N$ unblanched mango nectar, $B M N$ blanched mango nectar, $R I$ retention index 
heat treatment at $85{ }^{\circ} \mathrm{C} / 42 \mathrm{~s}$ in guava. However, other terpenoids compounds (isolimonene, $\alpha$-fenchene, and $\gamma$ terpinene), aldehydes ((E,Z)-2,6-nonadienal, $(E)$-2-nonenal, and 3-methyl-butanal), and alcohol (1-penten-3-ol) were formed in unblanched mango nectar, since their concentration is below the detection limit in blanched mango nectar. A possible explanation for these results could be that the enzymatic reactions occurred in unblanched mango nectar. A study performed by Dougherty (1971) also indicated that enzyme activity could be a possible factor in the deterioration of unheated or low-temperature-heated $\left(40{ }^{\circ} \mathrm{C} / 60 \mathrm{~min}\right)$ mango puree flavor quality.

Only two components selected (ethanol and 2-methyl-3buten-2-ol) were detected by positive VID coefficients in blanched mango nectar. From the individual plots (results not shown), ethanol, as a oxygenated volatile compound, was significantly increased after blanching in this study, with much higher concentration in blanched mango nectar. Moreover, it seems 2-methyl-3-buten-2-ol was formed due to blanching, since it was not detectable in unblanched mango nectar. Similar results have been reported. 2-methyl-3-Buten2-ol was detected in heat-treated $\left(50^{\circ} \mathrm{C} / 35 \mathrm{~min}\right)$ mangosteen fruit, whereas in fresh samples, its concentration was below the detention limit (Laohakunjit et al. 2007). Formation of 2methyl-3-buten-2-ol during blanching may be due to isoprene oxidation which could be found in mango (Jardine et al. 2013).

In this context, it can be concluded that there is a clear difference in volatile between unblanched and blanched mango nectar, which could mainly be due to possible thermal degradation of existing terpenoids as a result of blanching and formation of new components resulting from enzymatic reaction in unblanched mango nectar.

\section{Screening the Effect of a Range of Different Processing}

Technologies and Intensities

As explained in the section on "Processing Conditions," mango nectar was subjected to different conditions of processing: no processing (control), high pressure processing at $600 \mathrm{MPa} /$ $1 \mathrm{~min}$ (HP1), high pressure processing at $600 \mathrm{MPa} / 3 \mathrm{~min}$ (HP2), and thermal processing according to different pasteurization values $F_{85}^{8.3{ }^{\circ} \mathrm{C}}=5 \mathrm{~min}(\mathrm{TP} 1)$ and $F_{93.3^{\circ}{ }^{\circ} \mathrm{C}}^{\circ}=15 \mathrm{~min}(\mathrm{TP} 2)$.

To compare the effect of processing technologies and intensities on mango nectar per blanching condition, volatile changes over the whole range of the processing conditions were studied. Biplots based on PLS-DA are shown in Fig. 5 with LV1 and LV2.

For unblanched mango nectar, a clear separation between control, high hydrostatic pressure, and thermally processed samples can be seen, indicating important differences in their respective volatile profiles. LV1 describes differences between the control and the treated classes, while LV2 explains the classification between high hydrostatic pressure and

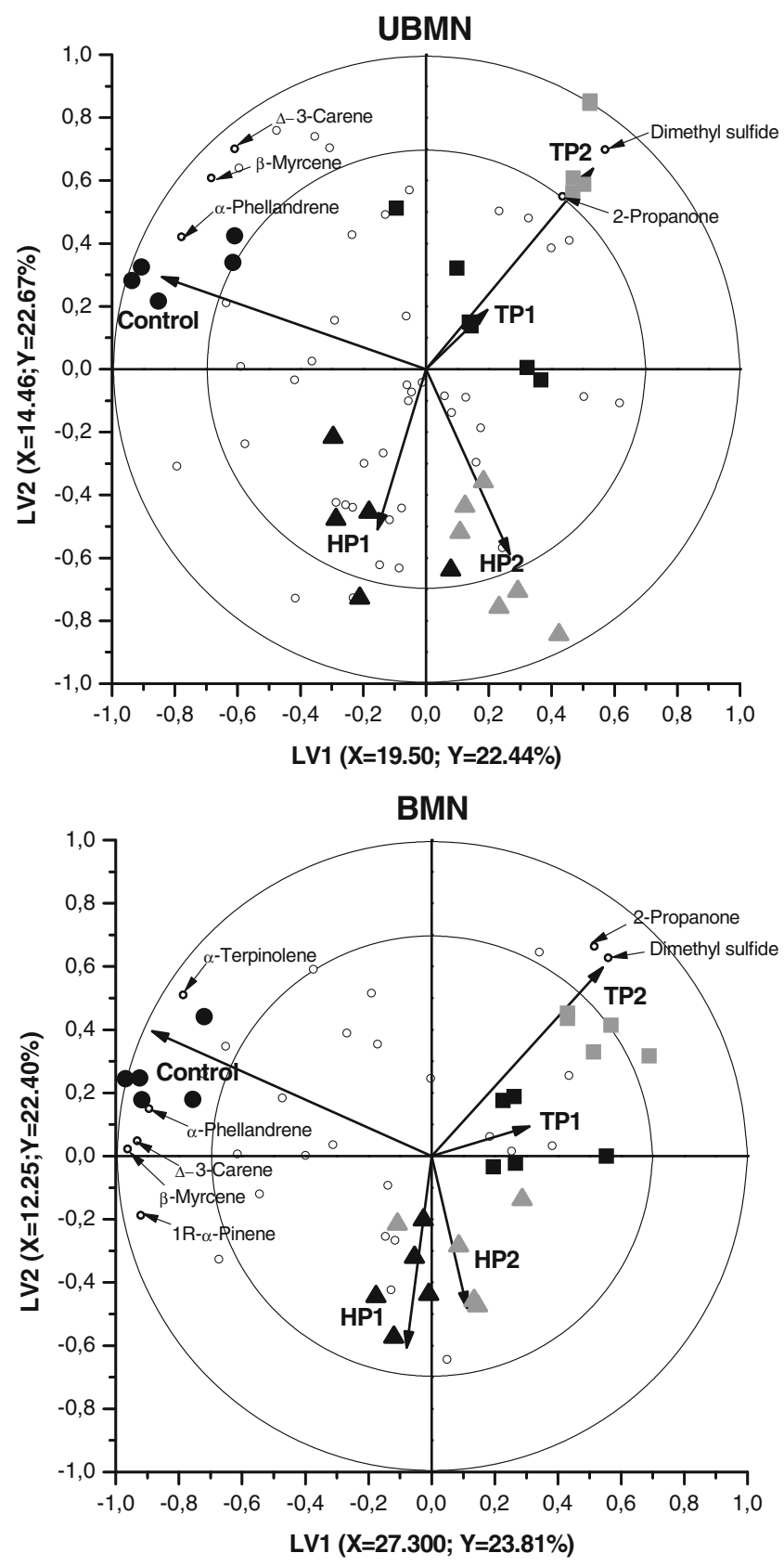

Fig. 5 Bi-plots based on PLS-DA describing the impact of different processing types and intensity, for unblanched and blanched mango nectar. The open circles represent the headspace components, of which only the selected discriminant components (bold open circles) are named (Table 2). The correlation loadings for the categorical $Y$-variables are represented as vectors. The $X$ - and $Y$-variance explained by each $\mathrm{LV}$ are indicated in the respective axes

thermal processing classes. These results showed that both high hydrostatic pressure and thermal processing may affect mango nectar volatiles, but could result in different processinduced chemical changes (being classified as two classes in the bi-plot). In addition to a clear separation among different processing conditions, a clear isolation within the class of high hydrostatic pressure and thermal processing treated mango 
nectars was noted. According to respective correlation loadings in the bi-plot, TP1 $\left(F_{85}^{8.3}{ }^{\circ} \mathrm{C} C=5 \mathrm{~min}\right)$-treated samples projected much closer to the control class compared to TP2 $\left(F_{93.3}^{8.3{ }^{\circ} \mathrm{C}}=15 \mathrm{~min}\right)$-treated samples, and HP1 (600 MPa/ $1 \mathrm{~min}$ )-treated samples situated closer to the control class compared to HP2 (600 MPa/3 min)-treated samples. That is, the changes in mango nectar volatiles increase with increasing processing intensity, both for high hydrostatic pressure and thermal processing. A comparable observation was previously reported by Vervoort et al. (2013) that important impact differences between high hydrostatic pressure and thermal processing on carrots were revealed, which became more pronounced upon increasing processing intensity.

To find out the discriminative components for the classification of differently treated unblanched mango nectar, adequately describing the impact of processing technologies and intensities, VID coefficients were calculated (Table 2). These selected components are also marked in the bi-plot in Fig. 5. Five volatiles were selected through the VID procedure for unblanched mango nectar (three for control samples, two for TP2-treated samples), while no volatiles detected those that met the requirements of the VID procedure were found for HP1-, HP2-, and TP1-treated samples. $\beta$-Myrcene, $\alpha$ phellandrene, and $\Delta$-3-carene were found with positive VID coefficients in control samples. From the individual plots (results not shown), their concentration decreased significantly by both high hydrostatic pressure and thermal processing, but no significant differences were observed among different processing conditions. It seems that both high hydrostatic pressure and thermal processing enhanced the degradation of naturally existing mango nectar terpenoids. Similar results were reported by Kebede et al. (2013a) showing that the degradation of terpenoids was increased by thermal and high pressure high-temperature treatments in green vegetables. Dimethyl sulfide and acetone were the only two components selected with positive VID coefficients for TP2-treated unblanched mango nectar. According to the individual plot (results not shown), the concentration of acetone appeared to be significantly higher in TP2-treated samples than control samples, while there were no significant changes after HP1, HP2, and TP1 treatment. This can possibly be linked to thermal-induced unsaturated fatty acid (i.e., acetoacetic acid) degradation reactions, caused by intensive thermal processing condition of TP2. The results were supported by Cremer and Eichner (2000) that acetone could be formed as a function of heating time at $90^{\circ} \mathrm{C}$ in commercially available spice paprika powder. Moreover, from the individual plots (Fig. 6), it seems that in this study, the sulfur-containing compound dimethyl sulfide was formed as a result of thermal processing in unblanched mango nectar, since its concentration was below the detection limit in control and high pressure-treated samples. Vervoort et al. (2013) found that dimethyl sulfide was significantly more produced during thermal treatment, than during equivalent high pressure treatment of carrots. The formation of dimethyl sulfide could be from thermal degradation of $S$-methylmethionine, an amino acid existing in mango nectar (Jin et al. 1999; Kubec et al. 1998). In this study, the thermal-induced formation was enhanced with increasing thermal intensity, with TP2-treated samples showing much higher concentration. Cremer and Eichner (2000) reported that the formation of dimethyl sulfide followed first-order kinetics as a function of heating temperature and time, and the maximum amount of dimethyl sulfide was observed at $110{ }^{\circ} \mathrm{C}$ for $90 \mathrm{~min}$. Kebede et al. (2013a) also reported that formation of sulfur-containing compounds (including dimethyl sulfide) in broccoli might increase as a function of temperature.

With respect to blanched mango nectar, the overall picture in the bi-plot is similar compared to unblanched mango nectar (Fig. 5), where LV1 explains the classification between

coefficients, where a positive VID coefficient indicates a higher concentration for that class. The retention index (RI) of components is also listed
Table 2 Discriminative headspace components, selected through VID procedure, for UBMN and BMN over all treatment conditions. The headspace components are listed in a decreasing order of VID

\begin{tabular}{|c|c|c|c|c|c|c|c|c|c|c|c|c|c|c|c|}
\hline & \multicolumn{3}{|c|}{ Control } & \multicolumn{3}{|l|}{ HP1 } & \multicolumn{3}{|l|}{ HP2 } & \multicolumn{3}{|l|}{ TP1 } & \multicolumn{3}{|l|}{$\mathrm{TP} 2$} \\
\hline & VID & Identity & RI & VID & Identity & RI & VID & Identity & RI & VID & Identity & RI & VID & Identity & RI \\
\hline \multirow[t]{3}{*}{ UBMN } & 0.874 & $\beta$-Myrcene & 991 & N.D. & & & N.D. & & & N.D. & & & 0.970 & Dimethyl sulfide & 669 \\
\hline & 0.874 & $\alpha$-Phellandrene & 1,006 & & & & & & & & & & 0.824 & Acetone & 665 \\
\hline & 0.838 & $\Delta$-3-Carene & 1,013 & & & & & & & & & & & & \\
\hline \multirow[t]{5}{*}{ BMN } & 0.924 & $\beta$-Myrcene & 991 & N.D. & & & N.D. & & & N.D. & & & 0.940 & Dimethyl sulfide & 669 \\
\hline & 0.903 & $\alpha$-Phellandrene & 1,006 & & & & & & & & & & 0.934 & Acetone & 665 \\
\hline & 0.899 & $\alpha$-Terpinolene & 1,093 & & & & & & & & & & & & \\
\hline & 0.889 & $\Delta$-3-Carene & 1,012 & & & & & & & & & & & & \\
\hline & 0.812 & 1R- $\alpha$-Pinene & 932 & & & & & & & & & & & & \\
\hline
\end{tabular}

$H P$ high pressure, $T P$ thermal processing, $R I$ retention index, $U B M N$ unblanched mango nectar, $B M N$ blanched mango nectar. $N . D$. no volatiles detected that met the requirements of the VID procedure 

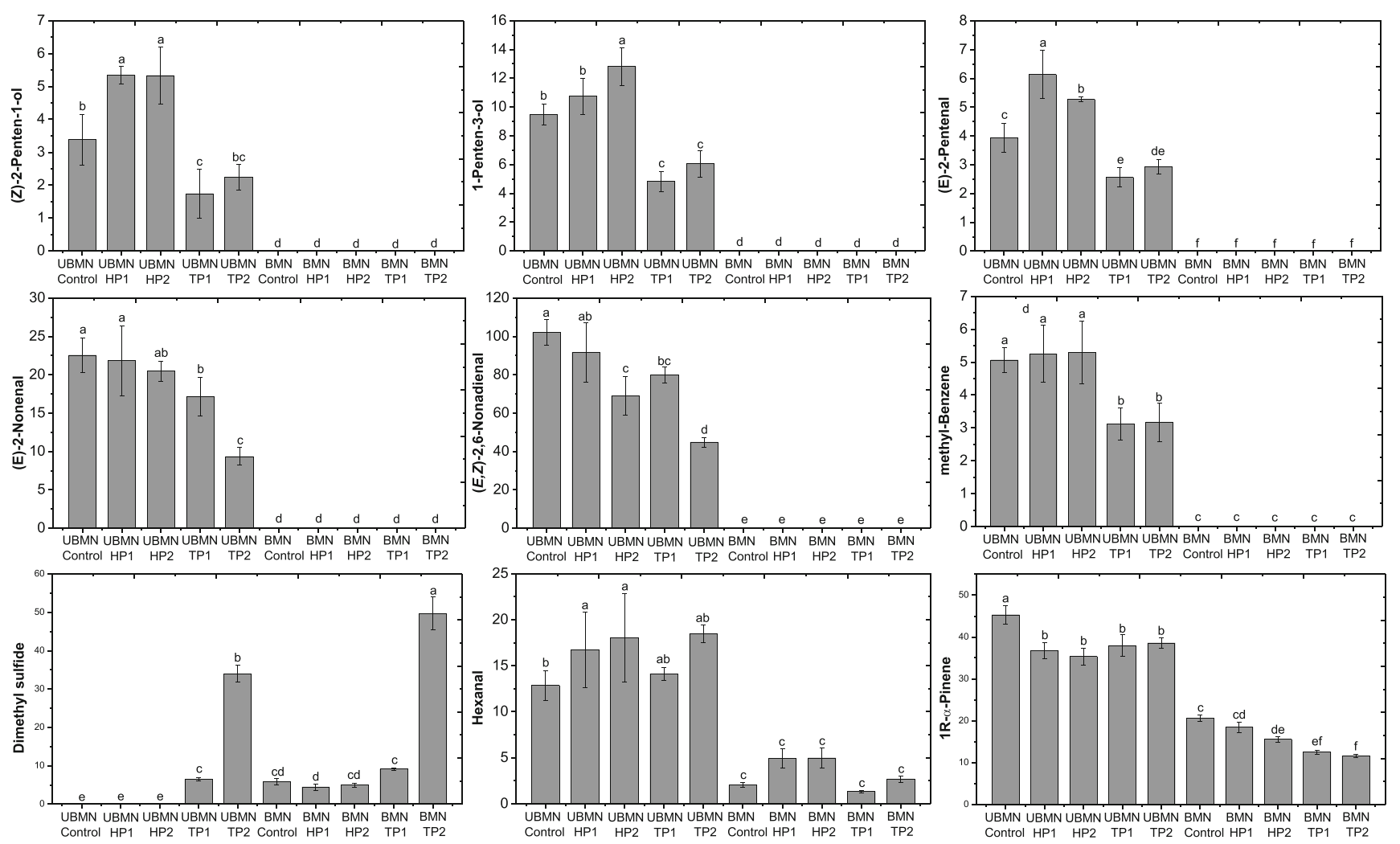

Fig. 6 Discriminative headspace components as a function of different treatments, selected through the VID procedure (Table 3) based on fair comparison for HP2 and TP1. The $Y$-axis indicates the peak area $\times 105$.

Error bars represent the standard error of analysis $(n=6)$. Significant differences $(p<0.05)$ are indicated with different letters

control and the treated classes, whereas LV2 classifies high hydrostatic pressure from thermally processed classes. According to the VID procedure, seven volatiles (five with positive VID coefficients for control samples, two for TP2treated samples) were selected as discriminative components. From the individual plots (results not shown), terpenoids ( $\beta$ myrcene, $\alpha$-phellandrene, $\Delta$-3-carene, $\alpha$-terpinolene, and $1 \mathrm{R}-\alpha$-pinene) were found to decrease significantly due to high pressure and thermal processing. The concentration of acetone was significantly increased by TP2, and no significant changes were observed after HP1, HP2, and TP1 treatment. For the terpenoid degradation and acetone formation, a similar hypothesis provided for unblanched mango nectar above could be used. Dimethyl sulfide was found in control blanched mango nectar, which could result from thermal degradation of $S$-methylmethionine during blanching. The compound increased significantly by thermal processing with increasing intensity, while it was not affected by high hydrostatic pressure.

Comparing the Process Effect of Fair High Hydrostatic Pressure and Thermal Processing Conditions

In this part, a comparison between high hydrostatic pressure and thermal processing on mango nectar is addressed for each blanching condition. To do so, it is crucial that relevant processing conditions are selected to guarantee a fair comparison (Vervoort et al. 2012; Kebede et al. 2013a). In this study, since HP2 and TP1 were selected based on an equivalent microbial safety, the comparison between these two processing conditions could be considered as fair, to zoom in to identify potential different effects of high hydrostatic pressure and thermal processing on mango nectar. From the authors' already published results using a targeted analytical approach (Liu et al. 2013b), differences between thermal and high pressure-treated mango nectar were only detected in the lightness $\left(L^{*}\right)$, while no differences were found in antioxidant capacity, L-ascorbic acid, sodium erythorbate, total phenols, total carotenoids, the redness $\left(a^{*}\right)$, the yellowness $\left(b^{*}\right)$, and browning degree. From the bi-plots in Fig. 5 in this study, we already observe that differences between the volatile profiles of HP2- and TP1-treated samples could be found; thus, headspace components might occur with significant differences. To find out the most important ones among them, adequately describing the difference between HP2- and TP1-treated mango nectar, a new PLS-DA model was constructed for HP2and TP1-treated samples (results not shown) per blanching condition. Discriminative components selected by the VID procedure are shown in Table 3, and they were all displayed individually as a function of all the processing conditions 
Table 3 Discriminative headspace components, for equivalent comparison of HP2- and TP1-treated samples. The headspace components are listed in a decreasing order of VID coefficient, where a positive VID coefficient indicates a higher concentration for that class. The retention index (RI) of components is also listed

\begin{tabular}{|c|c|c|c|c|c|c|}
\hline & \multicolumn{3}{|l|}{ HP2 } & \multicolumn{3}{|l|}{ TP1 } \\
\hline & VID & Identity & RI & VID & Identity & RI \\
\hline \multirow[t]{6}{*}{ UBMN } & 0.973 & 1-Penten-3-ol & 718 & 0.878 & Dimethyl sulfide & 669 \\
\hline & 0.935 & (Z)-2-Penten-1-ol & 776 & & & \\
\hline & 0.908 & (E)-2-Pentenal & 765 & & & \\
\hline & 0.895 & (E)-2-Nonenal & 1,162 & & & \\
\hline & 0.875 & methyl-Benzene & 774 & & & \\
\hline & 0.875 & $(E, Z)-2,6$-Nonadienal & 1,156 & & & \\
\hline \multirow[t]{2}{*}{ BMN } & 0.917 & Hexanal & 801 & & & \\
\hline & 0.822 & 1R- $\alpha$-Pinene & 932 & & & \\
\hline
\end{tabular}

$H P$ high pressure, $T P$ thermal processing, $R I$ retention index, $U B M N$ unblanched mango nectar, $B M N$ blanched mango nectar

(Fig. 6), helping to uncover all possible process-induced changes.

Seven components were selected by the VID procedure for unblanched mango nectar. For most of them, except dimethyl sulfide (already discussed above), a pronounced decrease was found as a result of thermal processing, which could also be proven from Table 1 indicating that a considerable number of them were already identified as discriminative components for blanching. Components selected with positive VID coefficients in the HP2 class are alcohols (1-penten-3-ol and (Z)2-penten-1-ol), aldehydes ((E)-2-pentenal, $(E)$-2-nonenal, and (E,Z)-2,6-nonadienal), and methyl-benzene. As shown in the individual plots (Fig. 6), all of these components in control unblanched mango nectar could result from enzymatic reactions, as they were below the detection limit in case of blanched mango nectar. As reported in previous literature, lipoxygenase and hydroperoxide lyase, which are naturally present in mango material, are partly responsible for the oxidation of polyunsaturated fatty acids (Oey et al. 2008a). Changes of these components after high hydrostatic pressure and thermal processing were different. Concentrations of $(E)$ 2-nonenal and $(E, Z)$-2,6-nonadienal seemed to decrease with increasing processing intensity, both for high hydrostatic pressure and thermal processing. These two components were identified as odor-active volatile compounds in mango (Pino 2012), and they could easily contribute to mango flavor since they generally have very low odor thresholds $(0.02$ and $0.08 \mathrm{ppb}$ ) and the highest odor activity values of all volatiles in different mango cultivars as reported by Pino and Mesa (2006). However, in this study, there were no significant differences in their concentrations between HP2- and TP1treated samples. Changes of 1-penten-3-ol, (Z)-2-penten-1-ol, and $(E)$-2-pentenal were found more interesting in this study. They were significantly decreased by thermal processing (TP1-treated samples) while increased by high pressure processing (HP2-treated samples). The formation of these aromatic aldehydes and alcohols can be linked to processing-induced unsaturated fatty acid oxidation reactions. This observation is in agreement with reports that high hydrostatic pressure enhances oxidation of free fatty acids leading to increased concentration of aldehyde and ketone volatile compounds (Oey et al. 2008a; Kebede et al. 2013a).

Only two components (1R- $\alpha$-pinene and hexanal) were selected as discriminant components for blanched mango nectar, showing positive VID coefficients for the HP2 class. This is not very unexpected, because as discussed in the section on the effect of blanching, the blanched mango nectar samples had already been stabilized by blanching $\left(95^{\circ} \mathrm{C} /\right.$ $8 \mathrm{~min}$ ), which was much more intensive than the subsequent processing of HP2 $(600 \mathrm{MPa} / 3 \mathrm{~min})$ and TP1 $\left(F_{85}^{8.3}{ }^{\circ} \mathrm{C} C=5 \mathrm{~min}\right)$. According to individual compound plots (Fig. 6), no significant difference was found in hexane between HP2 and TP1 processing conditions. 1R- $\alpha$-Pinene was found to decrease significantly after high hydrostatic pressure and thermal processing, while there were no significant differences between HP2- and TP1-treated samples. The decrease of $1 \mathrm{R}-\alpha$-pinene could be attributed to high hydrostatic pressure and thermal processing-induced terpenoid degradation.

\section{Conclusions}

This work demonstrates that headspace GC-MS fingerprinting could be a useful tool in screening the different effects of distinct processing technologies and intensities on the headspace food fraction to uncover different process-induced chemical changes, for example, in processed mango nectar. This method provides classifications of mango nectar samples even if they are very similar, as a comprehensive, unbiased methodology.

Using this method, this study could distinguish a clear effect of blanching on mango nectar volatiles, which could 
mainly be attributed to thermal degradation of existing terpenoids and the formation of new components resulting from enzymatic reaction in unblanched mango nectar. Both high hydrostatic pressure and thermal processing could change mango nectar volatiles, and these effects were even pronounced if the processing intensity was increased. Based on a fair comparison, different process-induced chemical changes were detected. For unblanched mango nectar, thermal processing seems to favor the formation of sulfur-containing compounds, while high hydrostatic pressure seems to enhance the oxidation of free fatty acids in mango nectar. However, for blanched mango nectar, the differences between high hydrostatic pressure and thermal processing were less significant compared to unblanched samples, since the treatment conditions used were quite milder compared to the blanching condition undertaken.

Based on these results obtained, more interesting future challenges can be put forward: (1) it can be hypothesized that the differences in process-induced changes among the technologies could become even more pronounced when applying sterilization conditions; (2) a kinetic study of the discriminative compounds selected by the VID procedure could be an essential next step; (3) sensory evaluation assessing the actual contribution of these compounds to sample flavor needs to be studied; and (4) volatile changes during posttreatment storage should be evaluated.

Acknowledgments This work is partially supported by a scholarship from China Scholarship Council (CSC) under grant 201206350127. Fengxia Liu is an exchange Ph.D. student in KU Leuven, funded by CSC. Tara Grauwet is a postdoctoral researcher funded by the Research Foundation Flanders (FWO-Vlaanderen).

\section{References}

Ahmed, J., Ramaswanmy, H. S., \& Hiremath, N. (2005). The effect of high pressure treatment on rheological characteristics and colour of mango pulp. International Journal of Food Science and Technology, 40(8), 885-895.

Bedair, M., \& Sumner, L. W. (2008). Current and emerging massspectrometry technologies for metabolomics. TrAC Trends in Analytical Chemistry, 27(3), 238-250.

Chen, J. P., Tai, C. Y., \& Chen, B. H. (2007). Effects of different drying treatments on the stability of carotenoids in Taiwanese mango (Mangifera indica L.). Food Chemistry, 100(3), 1005-1010.

Correa, M. I. C., Chaves, J. P. B., Jham, G. N., Ramos, A. M., Minim, V. P. R., \& Yokota, S. R. C. (2009). Changes in guava (Psidium guajava L. var. Paluma) nectar volatile compounds concentration due to thermal processing and storage. Food Science and Technology, 30(4), 1061-1068.

Cremer, D. R., \& Eichner, K. (2000). Formation of volatile compounds during heating of spice paprika (Capsicum annuum) powder. Journal of Agricultural and Food Chemistry, 48(6), 2454-2460.

Dalmadi, I., Polyak-Feher, K., \& Farkas, J. (2007). Effects of pressureand thermal-pasteurization on volatiles of some berry fruits. High Pressure Research, 27(1), 169-171.
Dettmer, K., Aronov, P. A., \& Hammock, B. D. (2007). Mass spectrometry-based metabolomics. Mass Spectrometry Reviews, 26(1), 51-78.

Dougherty, R. (1971). Taste panel response to flavor of heated mango puree. In: Proc. Fla. Sta. Hort. Soc. pp 250-257.

Gimenez, J., Kajda, P., Margomenou, L., Piggott, J. R., \& Zabetakis, I. (2001). A study on the colour and sensory attributes of high-hydrostatic-pressure jams as compared with traditional jams. Journal of the Science of Food and Agriculture, 81(13), 1228-1234.

Herrero, M., Simó, C., García-Cañas, V., Ibáñez, E., \& Cifuentes, A. (2012). Foodomics: MS-based strategies in modern food science and nutrition. Mass Spectrometry Reviews, 31(1), 49-69.

Hiremath, N. D., \& Ramaswamy, H. S. (2012). High-pressure destruction kinetics of spoilage and pathogenic microorganisms in mango juice. Journal of Food Processing and Preservation, 36(2), 113-125.

Huang, W., Bi, X., Zhang, X., Liao, X., Hu, X., \& Wu, J. (2013). Comparative study of enzymes, phenolics, carotenoids and color of apricot nectars treated by high hydrostatic pressure and high temperature short time. Innovative Food Science \& Emerging Technologies, 18, 74-82.

Jardine, K. J., Meyers, K., Abrell, L., Alves, E. G., Yanez Serrano, A. M., Kesselmeier, J., et al. (2013). Emissions of putative isoprene oxidation products from mango branches under abiotic stress. Journal of Experimental Botany, 64(12), 3669-3679.

Jin, Y., Wang, M., Rosen, R. T., \& Ho, C.-T. (1999). Thermal degradation of sulforaphane in aqueous solution. Journal of Agricultural and Food Chemistry, 47(8), 3121-3123.

Kebede, B. T., Grauwet, T., Tabilo-Munizaga, G., Palmers, S., Vervoort, L., Hendrickx, M., et al. (2013a). Headspace components that discriminate between thermal and high pressure high temperature treated green vegetables: identification and linkage to possible process-induced chemical changes. Food Chemistry, 141(3), 1603-1613.

Kebede, B. T., Grauwet, T., Mutsokoti, L., Palmers, S., Vervoort, L., Hendrickx, M., et al. (2013b). Comparing the impact of high pressure high temperature and thermal sterilization on the volatile fingerprint of onion, potato, pumpkin and red beet. Food Research International, 56, 218-225. doi:10.1016/j.foodres.2013.12.034.

Kebede, B. T., Grauwet, T., Palmers, S., Vervoort, L., Carle, R., Hendrickx, M., et al. (2013c). Effect of high pressure high temperature processing on the volatile fraction of differently coloured carrots. Food Chemistry. doi:10.1016/j.foodchem.2013.12.061.

Kim, Y., Lounds-Singleton, A. J., \& Talcott, S. T. (2009). Antioxidant phytochemical and quality changes associated with hot water immersion treatment of mangoes (Mangifera indica L.). Food Chemistry, 115(3), 989-993.

Knorr, D., Froehling, A., Jaeger, H., Reineke, K., Schlueter, O., \& Schoessler, K. (2011). Emerging technologies in food processing. Annual Review of Food Science and Technology, 2, 203-235.

Kubec, R., Drhová, V., \& Velíšek, J. (1998). Thermal degradation of Smethylcysteine and its sulfoxide important flavor precursors of Brassica and Allium vegetables. Journal of Agricultural and Food Chemistry, 46(10), 4334-4340.

Laohakunjit, N., Kerdchoechuen, O., Matta, F. B., Silva, J. L., \& Holmes, W. E. (2007). Postharvest survey of volatile compounds in five tropical fruits using headspace-solid phase microextraction (HSSPME). HortScience, 42(2), 309-314.

Liu, R. H. (2003). Health benefits of fruit and vegetables are from additive and synergistic combinations of phytochemicals. The American Journal of Clinical Nutrition, 78(3), 517S-520S.

Liu, F. X., Wang, Y. T., Bi, X. F., Guo, X. F., Fu, S. F., \& Liao, X. J. (2013a). Comparison of microbial inactivation and rheological characteristics of mango pulp after high hydrostatic pressure treatment and high temperature short time treatment. Food and Bioprocess Technology, 6(10), 1-10.

Liu, F. X., Wang, Y. T., Li, R. J., Bi, X. F., \& Liao, X. J. (2013b). Effects of high hydrostatic pressure and high temperature short time on 
antioxidant activity, antioxidant compounds and color of mango nectars. Innovative Food Science and Emerging Technology. doi: 10.1016/j.ifset.2013.09.015.

Liu, F. X., Li, R. J., Wang, Y. T., Bi, X. F., Liao, X. J. (2013c). Effects of high hydrostatic pressure and high-temperature short-time on mango nectars: changes in microorganisms, acid invertase, 5hydroxymethylfurfural, sugars, viscosity, and cloud. Innovative Food Science and Emerging Technology doi:10.1016/j.ifset.2013.09.015.

Norton, T., \& Sun, D.-W. (2008). Recent advances in the use of high pressure as an effective processing technique in the food industry. Food and Bioprocess Technology, 1(1), 2-34.

Oey, I., Lille, M., Van Loey, A., \& Hendrickx, M. (2008a). Effect of highpressure processing on colour, texture and flavour of fruit- and vegetable-based food products: a review. Trends in Food Science \& Technology, 19(6), 320-328.

Oey, I., Van der Plancken, I., Van Loey, A., \& Hendrickx, M. (2008b). Does high pressure processing influence nutritional aspects of plant based food systems? Trends in Food Science \& Technology, 19(6), 300-308.

Parish, M. (1998). Orange juice quality after treatment by thermal pasteurization or isostatic high pressure. LWT-Food Science and Technology, 31(5), 439-442.

Pino, J. A. (2012). Odour-active compounds in mango (Mangifera indica L. cv. Corazón). International Journal of Food Science \& Technology, 47(9), 1944-1950.

Pino, J. A., \& Mesa, J. (2006). Contribution of volatile compounds to mango (Mangifera indica L.) aroma. Flavour and Fragrance Journal, 21(2), 207-213.

Rawson, A., Patras, A., Tiwari, B. K., Noci, F., Koutchma, T., \& Brunton, N. (2011). Effect of thermal and non-thermal processing technologies on the bioactive content of exotic fruits and their products: Review of recent advances. Food Research International, 44(7), 1875-1887.
Sánchez-Moreno, C., Plaza, L., De Ancos, B., \& Cano, M. P. (2006). Impact of high-pressure and traditional thermal processing of tomato purée on carotenoids, vitamin C and antioxidant activity. Journal of the Science of Food and Agriculture, 86(2), 171-179.

Santhirasegaram, V., Razali, Z., \& Somasundram, C. (2013). Effects of thermal treatment and sonication on quality attributes of Chokanan mango (Mangifera indica L.) juice. Ultrasonic Sonochemistry, 20(5), 1276-1282.

Singh, Z., Singh, R. K., Sane, V. A., \& Nath, P. (2013). Mangopostharvest biology and biotechnology. Critical Reviews in Plant Sciences, 32(4), 217-236.

Vásquez-Caicedo, A. L., Schilling, S., Carle, R., \& Neidhart, S. (2007). Effects of thermal processing and fruit matrix on $\beta$-carotene stability and enzyme inactivation during transformation of mangoes into purée and nectar. Food Chemistry, 102(4), 1172-1186.

Vervoort, L., Grauwet, T., Kebede, B. T., Van der Plancken, I., Timmermans, R., Hendrickx, M., et al. (2012). Headspace fingerprinting as an untargeted approach to compare novel and traditional processing technologies: a case-study on orange juice pasteurisation. Food Chemistry, 134(4), 2303-2312.

Vervoort, L., Grauwet, T., Njoroge, D. M., Van der Plancken, I., Matser, A., Hendrickx, M., et al. (2013). Comparing thermal and high pressure processing of carrots at different processing intensities by headspace fingerprinting. Innovative Food Science \& Emerging Technologies, 18, 31-42.

Wishart, D. S. (2008). Metabolomics: applications to food science and nutrition research. Trends in Food Science \& Technology, 19(9), 482-493.

Yen, G.-C., \& Lin, H.-T. (1999). Changes in volatile flavor components of guava juice with high-pressure treatment and heat processing and during storage. Journal of Agricultural and Food Chemistry, 47(5), 2082-2087. 